\title{
Novel water source for endolithic life in the hyperarid core of the Atacama Desert
}

\author{
J. Wierzchos ${ }^{1}$, A. F. Davila ${ }^{2}$, I. M. Sánchez-Almazo ${ }^{3}$, M. Hajnos ${ }^{4}$, R. Swieboda ${ }^{5}$, and C. Ascaso ${ }^{1}$ \\ ${ }^{1}$ Museo Nacional de Ciencias Naturales, MNCN-CSIC, Madrid, Spain \\ ${ }^{2}$ NASA Ames Research Center, Moffett Field, USA \\ ${ }^{3}$ Universidad de Granada CIC, Granada, Spain \\ ${ }^{4}$ Institute of Agrophysics PAN, Lublin, Poland \\ ${ }^{5}$ Medical University of Lublin, Lublin, Poland
}

Correspondence to: J. Wierzchos (j.wierzchos@mncn.csic.es)

Received: 29 February 2012 - Published in Biogeosciences Discuss.: 14 March 2012

Revised: 17 May 2012 - Accepted: 25 May 2012 - Published: 26 June 2012

\begin{abstract}
The hyperarid core of the Atacama Desert, Chile, is possibly the driest and most life-limited place on Earth, yet endolithic microorganisms thrive inside halite pinnacles that are part of ancient salt flats. The existence of this microbial community in an environment that excludes any other life forms suggests biological adaptation to high salinity and desiccation stress, and indicates an alternative source of water for life other than rainfall, fog or dew. Here, we show that halite endoliths obtain liquid water through spontaneous capillary condensation at relative humidity $(\mathrm{RH})$ much lower than the deliquescence $\mathrm{RH}$ of $\mathrm{NaCl}$. We describe how this condensation could occur inside nano-pores smaller than $100 \mathrm{~nm}$, in a newly characterized halite phase that is intimately associated with the endolithic aggregates. This nanoporous phase helps retain liquid water for long periods of time by preventing its evaporation even in conditions of utmost dryness. Our results explain how life has colonized and adapted to one of the most extreme environments on our planet, expanding the water activity envelope for life on Earth, and broadening the spectrum of possible habitats for life beyond our planet.
\end{abstract}

\section{Introduction}

Water is the single most important requirement for life on Earth. While specialized organisms can exist in all but the most arid parts of the Earth, at some point water is too scarce to permit the full range of functions necessary to sustain viable populations of organisms, and biological adaptation to desiccation is no longer possible. We call this threshold the dry limit of life. Understanding the dry limit of life is critical to constrain the water activity envelope for life on Earth, and the possibility of life elsewhere.

There are two known strategies for water acquisition and survival by organisms in extremely dry environments. The first is to colonize substrates where moisture is retained after meager precipitations or snowmelt (Friedmann, 1982), dew deposition (Büdel et al., 2008; Lange et al., 1994; Kidron, 2000), or fog events (Henschel and Seely, 2008; Azúa-Bustos et al., 2011). The undersides of translucent quartz, or the interior of porous sandstones, are examples of such substrates. A second strategy, exemplified by most lichens and some cyanobacteria, is to supplement liquid water from air humidity (Lange et al., 1994; Palmer and Friedmann, 1990a, b). These strategies have worked successfully in all hot and cold deserts on Earth, except in some parts of the Atacama Desert, in Chile, which appear to be too dry even for these strategies to be effective.

The hyperarid core of the Atacama Desert, located between $20^{\circ} \mathrm{S}$ and $24^{\circ} \mathrm{S}$, receives less than $1 \mathrm{~mm} \mathrm{yr}^{-1}$ of rainfall (McKay et al., 2003). Soils here are one of the most extreme environments for life on Earth (Navarro-González et al., 2003), with extremely low concentrations of microorganisms (Navarro-González et al., 2003; Connon et al., 2007; Lester et al., 2007) and trace amounts of degraded, relic organic compounds (Navarro-González et al., 2003; Ewing et al., 2008). The varnish on surface rocks contains 
scarce quantities of cryptoendolithic bacteria (Kuhlman et al., 2008), whereas epilithic lichens and hypolithic microorganisms, found abundantly outside the hyperarid core (Warren-Rhodes et al., 2006; Wierzchos et al., 2011; AzúaBustos et al., 2011), are virtually absent within it (WarrenRhodes et al., 2006; Wierzchos et al., 2011). This region has been labeled the driest place on Earth and is considered to be close, or beyond, the dry limit of life.

Surprisingly abundant photosynthetic life has been recently found in the hyperarid core (Wierzchos et al., 2006), inside halite deposits that are part of Neogene salt-encrusted playas, also known as salares (Pueyo et al., 2001). These halite deposits have been isolated from any significant source of surface or ground water for the entire Quaternary, and possibly longer (Pueyo et al., 2001). The halite is shaped in the form of small pinnacles and contains endolithic (rock interior sensu Golubic et al., 1981 and Nienow, 2009) communities of photosynthetic cyanobacteria, along with heterotrophic bacteria and archaea (Wierzchos et al., 2006; de los Ríos et al., 2010). Chroococcidiopsis-like cells were the only cyanobacteria found inside the pinnacles, and phylogenetic studies have revealed their closer genetic affinity to Halothece genus (de los Ríos et al., 2010). Gene sequences of the heterotrophic bacteria and archaea indicated their proximity to microorganisms found in other hypersaline environments (de los Ríos et al., 2010). The presence of a microbial community in an environment that excludes any other life suggests that halite endoliths utilize a third strategy for survival under extreme water stress.

Davila et al. (2008) showed that water vapor condenses within the halite pinnacles at relative humidity $(\mathrm{RH})$ levels, which correspond to the deliquescence point of $\mathrm{NaCl}$ $(\mathrm{RH}=75 \%)$, and suggested this as a potential water source for the endolithic microorganisms inside the salt. This model implies a close link between the rock substrate and the endolithic communities, and departs from other lithic environments in that the rock substrate itself supplements the liquid water.

However, there are still many open questions with regard to this unique endolithic habitat, such as the exact mechanism of water acquisition, the dynamics of liquid water inside the pinnacles, or the interplay between the endolithic communities and the salt substrate. To address these questions, the micro-environmental conditions inside pinnacles were monitored at high temporal resolution for a period of one year. We also conducted non-destructive microscopy investigations to characterize the endolithic habitat from the macro to the micro scale. Our results indicate new mechanisms of water condensation and retention within the halite, and provide further evidence that hygroscopic minerals expand the limits of life in extremely dry environments. The significance of understanding this novel water source for life within halite pinnacles from the hyperarid core of the Atacama Desert resides in the fact that it might push the dry limit of life outside of the boundaries of our planet.

\section{Materials and methods}

\subsection{Sampling site}

The study site was located in the Yungay region of the Atacama Desert $\left(24^{\circ} 05^{\prime} 01^{\prime \prime} \mathrm{S}, 069^{\circ} 54^{\prime} 52^{\prime \prime} \mathrm{W}\right.$, elevation $\left.969 \mathrm{~m}\right)$, $75 \mathrm{~km}$ southeast of the city of Antofagasta, and about $60 \mathrm{~km}$ from the Pacific Ocean. Yungay receives negligible rain ( $<1 \mathrm{~mm} \mathrm{yr}^{-1}$, McKay et al., 2003), and the coastal mountains block the marine fog, the so-called camanchaca, which only reaches Yungay area in extremely rare occasions. Samples of halite pinnacles were collected for laboratory investigations during a field expedition in January 2010.

\subsection{Monitoring of micro-environmental parameters}

Microclimate data were collected in situ over a period of one year from January 2010 simultaneously inside and outside a representative halite pinnacle using an Onset $\mathrm{HOBO}^{\circledR}$ Weather Station Data Logger (H21-001) connected to a SolarStream ${ }^{\circledR}$ solar-powered transmitter for data transmission by the Iridium Satellite Constellation (Fig. 1a). The array of sensors included photosynthetic active radiation (PAR), temperature $(T)$, relative humidity $(\mathrm{RH})$, electrical conductivity (EC) and a rainfall gauge. Extensive details and images of this setup are provided in the Supplement.

\subsection{Mercury intrusion porosimetry}

The porosity and pore size distribution of halite pinnacles were estimated by means of mercury intrusion porosimetry (MIP) (Benavente et al., 2003; Hajnos et al., 2006). MIP was performed on 10 samples for each zone and all data assumed the cylindrical geometry of pores. A Micromeritics (AutoPore IV 9500) instrument was used to determine connected porosity, pore size distribution and mean pore size in the range of equivalent radii of $0.0015 \mu \mathrm{m}$ to $173 \mu \mathrm{m}$. In the Washburn (or Laplace) equation, a mercury surface tension value of $0.48 \mathrm{~N} \mathrm{~m}^{-1}$ and salt-mercury contact angle of $141.3^{\circ}$ were used, respectively. Small blocks of $\mathrm{NaCl}$ from surface and colonized zones were first air-dried at $20^{\circ} \mathrm{C}$ and $20 \%$ of $\mathrm{RH}$ for one week and later oven-dried to $105^{\circ} \mathrm{C}$ for $24 \mathrm{~h}$ and degassed in a vacuum under a pressure of $1.33 \mathrm{~Pa}$ at a temperature of $20^{\circ} \mathrm{C}$ before analysis. Porosity (total porosity $\%$ ) was then determined as the weight-normalized volume of mercury intruded in the sample.

\subsection{Fluorescence microscopy}

Fluorescence microscopy (FM) was used to identify and characterize the endolithic communities, and to study the distribution of cells inside the pinnacles. Cross sections of halite pinnacles were stained with $20 \mu$ of SYBR Green I (SBI) (Molecular Probes), a fluorochrome used for the specific staining of nucleic acid structures of bacteria cells. Bright field images and SYBR Green fluorescence (green 


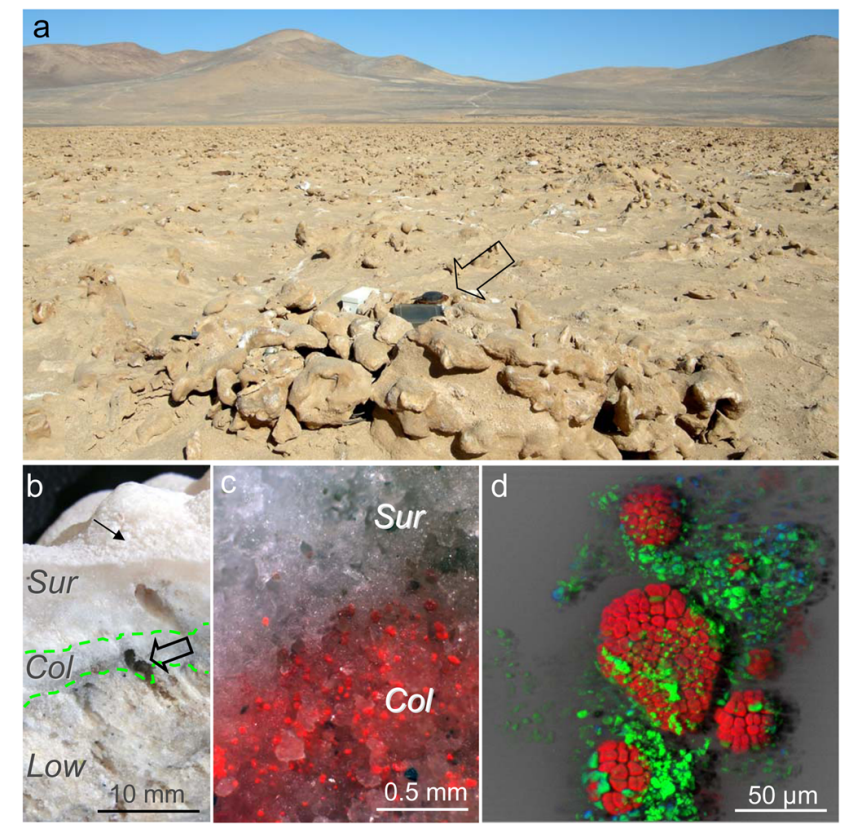

Fig. 1. Halite pinnacles and their endolithic microbial community in the Yungay region of the Atacama Desert. (a) Group of halite pinnacles with the microweather station in the foreground (open arrow). (b) Fractured halite pinnacle with a non-colonized outer layer (Sur), colonized intermediate zone ( $\mathrm{Col})$ with larger pores (open arrow), and a non-colonized inner layer (Low). Note the halite efflorescence on the pinnacle surface (black arrow), which indicates recent brine evaporation. (c) Fluorescence microscopy (FM) reveals the sharp boundary between the non-colonized outer layer and the colonized zone (red autofluorescence of cyanobacterial aggregates). (d) In situ 3-D FM-SIM image of cyanobacterial aggregates (red autofluorescence signal), and associated heterotrophic bacteria and archaea (SYBR Green stained DNA structures green signal).

signal) and photosynthetic pigments autofluorescence (red signal) were visualized with Zeiss Axio Imager D1 fluorescence microscope equipped with Plan-Apo $60 \times / 1.4$ Zeiss oil-immersion objective. Specific set of filters was used for green and red signal visualization: eGFP (Zeiss Filter Set 38; Ex/Em: 450-490/500-550 nm) and for rhodamine (Zeiss Filter Set 20; Ex/Em: 540-552/567-647 nm), respectively. Images were recorded with CCD AxioCam HRc (Zeiss) camera and AxioVision 4.7 (Zeiss) software. A detailed description of the FM procedure, as well as applied structural illumination microscopy mode (SIM), can be found in Wierzchos et al. (2011).

\subsection{Low temperature scanning electron microscopy}

We used a low temperature scanning electron microscope (LT-SEM) to study the internal structure of colonized halite pinnacles in their natural state, minimizing sample preparation artifacts. The LT-SEM was equipped with imaging systems using secondary electrons (SE) and backscattered elec- trons (BSE) detectors, as well as an X-ray energy dispersive spectroscopy (EDS) system. The cryotransfer system of the LT-SEM (CT1500 Cryotrans, Oxford) was composed of a plunge-freezing console, a specimen transfer device, a cryopreparation chamber with cold knife and coating system, and a cold stage in the SEM chamber. This setup allowed quenching and stabilizing wet microstructures by ice vitrification (i.e. rapid cooling), transferring and maintaining the sample in cryogenic condition during the whole experiment, coldknife fracturing of the sample, and its surface metal-coating. Block samples (about $10 \times 10 \times 10 \mathrm{~mm}$ ) of halite from surface and colonized zones were equilibrated for $48 \mathrm{~h}$ at different RH levels $(0,20,37,65,70$ or $75 \%)$ using silica gel as desiccant for $\mathrm{RH}=0 \%$ and different mixtures of glycerol and water for higher $\mathrm{RH}$ values. The corresponding equilibration $\mathrm{RH}$ values were controlled and recorded using $\mathrm{RH} / T$ sensors $\left(\mathrm{HOBO}^{\circledR}-\mathrm{U} 23\right.$ Pro v2; precision, $\left.\pm 2.5 \% \mathrm{RH} / \pm 0.2^{\circ} \mathrm{C}\right)$. Then, small fragments of halite samples $(1 \times 1 \times 2 \mathrm{~mm})$ were placed on the adjustable slit of the sample holder of the cryotransfer system and fixed to the holder using double-sided adhesive carbon tape. The samples were then plunged frozen in subcooled liquid nitrogen and transferred to the cryopreparation unit, where they were cryo-fractured at $-170^{\circ} \mathrm{C}$. Samples previously equilibrated at $75 \% \mathrm{RH}$ were etched (freeze-dried) for $2 \mathrm{~min}$ at $-90^{\circ} \mathrm{C}$. Samples equilibrated at RH lower than $75 \%$ were observed without etching in order to avoid the formation of secondary morphologies due to freeze-drying (i.e. sublimation) of small pockets of brine. The surface of all samples was gold sputter-coated and then transferred onto the cold stage of the SEM chamber. Fractured surfaces were observed under a DSM960 Zeiss SEM microscope at $-135^{\circ} \mathrm{C}$ under conditions of $15 \mathrm{kV}$ acceleration potential, $10 \mathrm{~mm}$ working distance and 5-10 nA probe current.

\subsection{High-resolution scanning electron microscopy}

The high-resolution scanning electron microscopy (HRSEM) technique was used in order to characterize in detail the fine structures within the halite. To that end, small halite samples (ca. $3 \times 3 \times 3 \mathrm{~mm}$ ) were dehydrated to $0 \% \mathrm{RH}$ by desiccation in silica gel for $48 \mathrm{~h}$. Subsequently, the samples were hand crushed, mounted on stubs and their fresh surface was covered by evaporated carbon. The samples were studied using Auriga field emission FIB-FESEM (Carl Zeiss SMT, Oberkochen, Germany) apparatus operating with inlens secondary electron detection mode (SE-inLens) under high vacuum and conditions of $3 \mathrm{kV}$ acceleration potential, 2.4-2.7 mm working distance and ESB grid current of $800 \mathrm{~V}$.

\subsection{Environmental scanning electron microscopy}

The environmental scanning electron microscope (ESEM) system allows recording secondary images under controlled water vapor pressures and temperature conditions up to water 
saturation $(\mathrm{RH}=100 \%)$. A Peltier device is attached to the microscope stage for a fine control of sample temperature. Gas pressure in the ESEM chamber is regulated by introducing water vapor, and accurately controlled by the environmental microscope valve and an exclusive dedicated vacuum pump. In our experiment, the total pressure in the sample chamber was always equal to the partial pressure of $\mathrm{H}_{2} \mathrm{O}$. Keeping a constant sample temperature at $5^{\circ} \mathrm{C}$ and changing the partial $\mathrm{H}_{2} \mathrm{O}$ pressure in the range of 0.7 to $8.75 \mathrm{mbar}$ (in steps of 0.13 mbar) during the experiment allowed us to adjust the RH between 2 and $100 \%$ inside the chamber. The constant temperature conditions, as well as controlled RH values inside the chamber, allowed us to attain sample visualization with minimal artifacts, and to reproduce natural oscillations of RH based on microclimate data.

Small blocks (ca. $3 \times 3 \times 3 \mathrm{~mm}$ ) of halite were separated from bigger halite fragments collected in the field, and kept inside hermetic boxes at a RH of $37 \%$ (controlled by RH/T sensors; $\mathrm{HOBO}^{\circledR}-\mathrm{U} 23$ Pro v2), which is the mean annual $\mathrm{RH}$ measured in the field. After that the small blocks were mounted on the stainless steel stub with double-sided carbon adhesive tape and left to equilibrate at $5^{\circ} \mathrm{C}$ for $15 \mathrm{~min}$. After equilibration, the sample was introduced in the ESEM chamber. Eight water vapor pressure purges were performed from $0.7 \mathrm{mbar}$ up to $4.7 \mathrm{mbar}$. These purges were strategically controlled to avoid sample moistening above the $\mathrm{RH}$ value of $37 \%$, keeping the $\mathrm{RH}$ of the sample during the purges approximate between $0 \%$ and $30 \%$. Initially, the sample was held for $30 \mathrm{~min}$ at low RH (e.g. $20 \%$ ) and the $\mathrm{RH}$ then increased to the deliquescence relative humidity (DRH) of halite $(75 \%)$ in $5 \%$ steps or smaller. After each pressure increase, the sample was left to equilibrate for several minutes before the pressure was raised again. During the whole experiment, we used a gaseous secondary electron detector (GSED) marketed by FEI company, which collects the secondary electrons with high efficiency. Design of this detector allows the study of the external micromorphology of fine halite structures with a chamber gas pressure up to 13 mbar. The GSED detector applied a positive bias to collect secondary electrons released by the sample surface after the primary electron beam penetrated the sample. During the travel of those secondary electrons to the detector, they collide with water vapor molecules that generate secondary electrons themselves producing an amplification of the signal (Thiel et al., 1997). This amplification is affected significantly by backscattered electrons. The images were digitalized and stored as single frame and/or as a digital video file to record any morphological changes occurring on the $\mathrm{NaCl}$ crystal surface as a function of water vapor pressure. After water film formation was observed at the DRH, the RH inside the ESEM chamber was reduced again to below the point of $\mathrm{NaCl}$ crystallization. All observations were conducted in a FEI Quanta 400 instrument under conditions of $15 \mathrm{kV}$ acceleration potential, 5-10 $\mathrm{mm}$ working distance.

\section{Results and discussion}

\subsection{Characterization of endolithic colonization inside halite pinnacles}

Generally, halite pinnacles are round-shaped, typically 20 $30 \mathrm{~cm}$ tall, and appear distributed in a seemingly random fashion (Fig. 1a). Their surface is coated with wind-blown silt and sand particles. Just beneath the surface, there is a non-colonized, light-colored layer approximately $10 \mathrm{~mm}$ thick (Fig. 1b), with an average pore radius of $42.65 \mathrm{~nm}$ (Table 1). Below that layer, there is an inner zone of variable thickness that contains the endolithic microbial colonies (Fig. 1c) with close spatial relations between the different taxa (Fig. 1d). This colonized zone has an average pore radius of $153.10 \mathrm{~nm}$. Below this colonized zone, there is a non-colonized layer mainly composed by halite and traces of quartz, feldspar, gypsum, glauberite and fine-grained sediment impurities as observed by DRX (not shown). Mercury intrusion porosimetry data (Table 1) reflect a layering within the halite in terms of pore size and pores size distribution. In fact, a noticeable fraction of the total porosity lies below a diameter of $100 \mathrm{~nm}$ (Table 1), particularly in the outer layer, which is also devoid of colonization. This was also confirmed by electron microscopy and helps explain the microclimate observations inside the pinnacles (see below). The layering and characteristic pore size distribution of the pinnacles are the result of small-scale water dynamics in the natural environment, and at the same time the small pores likely affect the way in which water is exchanged between the interior of the halite and the atmosphere, which ultimately controls the colonization. As such, results from mercury intrusion porosimetry point to an important role of small pore sizes in the habitability of halite pinnacles.

\subsection{Microclimate environment inside the halite pinnacles}

To address the sources and dynamics of liquid water in the halite pinnacles, we deployed an array of microweather sensors to monitor environmental conditions inside, on the surface and outside the pinnacles at a high temporal resolution for a one-year period (January 2010-January 2011). Open arrow in Fig. 1a shows the location of the microweather station installed among and within the halite pinnacles. Figure 2 shows the variation of monitored micro-environmental parameters, including PAR, $T, \mathrm{RH}$ and $\mathrm{EC}$. The rainfall gauge did not record any rain even in the course of one year, and the external PAR, RH and EC sensors did not record fog events, either from low PAR levels, near-saturation RH, or positive EC. Midday clouds were present on two days based on PAR data. The pinnacle surface temperature was monitored using a thermocouple $T$ sensor. Based on this surface temperature measurement and the air RH and air $T$ data, we can also rule 
Table 1. Mercury intrusion porosimetry data.

\begin{tabular}{|c|c|c|}
\hline & Superficial zone & Colonized zone \\
\hline Total intrusion volume ${ }^{\mathrm{a}}\left[\mathrm{ml} \mathrm{g}^{-1}\right]$ & $0.0489, \sigma=0.01$ & $0.1164, \sigma=0.01$ \\
\hline Total pore area $\left[\mathrm{m}^{2} \mathrm{~g}^{-1}\right]$ & $2.37, \sigma=0.77$ & $1.78, \sigma=0.63$ \\
\hline Median pore radius (vol.) [nm] & $3831.07, \sigma=1529$ & $6942.22, \sigma=1159$ \\
\hline Median pore radius (area) $[\mathrm{nm}]$ & $2.56, \sigma=0.74$ & $3.17, \sigma=1.42$ \\
\hline Average pore diameter $/ 2=$ radius $^{b}(4 \mathrm{~V} / \mathrm{A})[\mathrm{nm}]$ & $42.65, \sigma=9.15$ & $153.10, \sigma=87.08$ \\
\hline Bulk density ${ }^{\mathrm{c}}\left[\mathrm{g} \mathrm{cm}^{-3}\right]$ & $1.94, \sigma=0.06$ & $1.72, \sigma=0.04$ \\
\hline Total porosity ${ }^{\mathrm{d}}[\%]$ & $9.40, \sigma=2.14$ & $19.84, \sigma=1.84$ \\
\hline Total intrusion volume $\left[\mathrm{ml} \mathrm{g}^{-1}\right]$ for pores $<100 \mathrm{~nm}$ & 0.0057 & 0.0067 \\
\hline Fraction in $[\%]$ of total porosity for pores $<100 \mathrm{~nm}$ & 11.73 & 5.76 \\
\hline
\end{tabular}

${ }^{\mathrm{a}}$ Volume of $\mathrm{Hg}$ introduced for maximum (413 MPa) pressure; ${ }^{\mathrm{b}}$, the average pore diameter (4V/A) obtained by assuming that pore volume $\left(\mathrm{V}=\pi \mathrm{d}^{2} \mathrm{~L} / 4\right)$ is divided by the pore area $(A=\pi \mathrm{dL})$, the average pore diameter $(d)$ is equal to $4 \mathrm{~V} / \mathrm{A}$; ${ }^{\mathrm{c}}$, bulk density at $0.0036 \mathrm{MPa}$ pressure; ${ }^{\mathrm{d}}$, total porosity - the ratio of pore volume to apparent volume of the sample (calculated on the basis of the bulk density) expressed as a percentage.

Table 2. Micro-environmental data measured simultaneously outside and inside halite pinnacles in the Yungay region.

\begin{tabular}{|c|c|c|}
\hline Variable & Halite exterior & Halite interior \\
\hline Mean annual RH, \% & 34.75 & 54.74 \\
\hline Maximum annual RH, \% & 74.20 & 86.10 \\
\hline Minimum annual RH, \% & 2.90 & 2.20 \\
\hline$\sigma$ for $\mathrm{RH}$ measurements & 19.50 & 27.99 \\
\hline Mean annual $T,{ }^{\circ} \mathrm{C}$ & 18.03 & 17.94 \\
\hline Maximum annual $T,{ }^{\circ} \mathrm{C}$ & 45.06 & 51.00 \\
\hline Minimum annual $T,{ }^{\circ} \mathrm{C}$ & -6.17 & -9.47 \\
\hline$\sigma$ for $T$ measurements & 11.24 & 13.76 \\
\hline Annual wet events ${ }^{\mathrm{a}}, \mathrm{h} \mathrm{yr}^{-1}$ & 0 & 5362 \\
\hline Annual wet events ${ }^{\mathrm{b}}, \mathrm{h} \mathrm{yr}^{-1}$ & 0 & 3909 \\
\hline
\end{tabular}

a, for $\mathrm{EC}_{\text {In }}>0.0006$; ${ }^{\mathrm{b}}$, for $\mathrm{RH}_{\text {In }}>75 \%$.

out dew condensation on the surface of the pinnacle, based on the Magnus-Tetens formula.

Atmospheric RH (blue line in Fig. 2c) never exceeded $75 \%$, which is the beginning point of halite deliquescence (Davila et al., 2008, 2010; Tang and Munkelwitz, 1993; Ebert, 2002). The maximum RH recorded outside the pinnacles over the year was $74.2 \%$, and mean atmospheric $\mathrm{RH}$ was $34.8 \%$ (Table 2). Previous studies in the Yungay region have reported sporadically higher maximum RH values during fog or short rainfall events (McKay et al., 2003; Davila et al., 2008). Despite the absence of liquid water from rainfall precipitation, dew or higher than $75 \%$ atmospheric $\mathrm{RH}$ over the course of one year, positive EC signals on the surface and interior of halite pinnacle (Fig. 2d) (i.e. liquid water) and elevated RH values, frequently exceeding $80 \%$ (green line on Fig. 2c), on the interior of halite pinnacle were observed. Based on those, it is possible to differentiate two main stages of moisture conditions within the colonization zone of the pinnacles. The first, or dry, stage occurs when atmospheric RH remains below $40 \%$ for several days (blue line in
Fig. 3a), and the RH inside the pinnacle is comparably low (green line in Fig. 3a, and values below the pink diamond in Fig. 3b, and Supplementary Fig. S2). During the dry stage, the surface and interior of the pinnacle are completely dry, as evidenced by the null EC values (Fig. 3a). The second, or wet, stage occurs when atmospheric RH exceeds 50-55\% (white diamond on blue line in Fig. 3b), and this is reflected by an EC spike on the surface of the pinnacle (red line in Fig. 3b). If atmospheric RH rises to above $60 \%$, the spike in surface EC values is followed by high EC values also in the colonized zone (black line in Fig. 3b), indicating liquid water condensation inside the pinnacle. This EC spike in the colonized zone occurs when mean RH inside halite rises above $51.8 \%(\sigma=9.2 ; n=65)$ (black diamond in Fig. 3b and Supplementary Fig. S2). Wet stages always commence during the night or early morning, when air temperature drops and atmospheric RH rises, and can be as short-lived as tens of minutes or as long as days or weeks. Remarkably, the longest wet stage, when the EC probe recorded the presence of liquid water (as $\mathrm{NaCl}$ brine) inside the halite pinnacle, lasted 40 days (Supplementary Fig. S3).

Once the pinnacle interior reached the wet stage, $\mathrm{RH}$ values within the pinnacle remained between $75 \%$ and $86.1 \%$ (green lines in Fig. 3b, c), and the conductivity sensor registered its highest values (black lines in Fig. 3b, c), indicating significant amounts of pore-water brine within the colonized zone. It is important to note that, during wet stages, conditions inside the pinnacles appeared to be independent of the external conditions (Fig. 3b, c), which frequently remained extremely dry. The wet stage typically terminated when RH inside the pinnacle fell below $41.87 \%(\sigma=10.8, n=65)$ (values below the pink diamond in Fig. $3 b$ and Supplementary Fig. S2). At this point, the interior of the pinnacle dried up, as reflected by the null EC, and low $\mathrm{RH}$, values.

We note that the occurrences of dry/wet stages were derived from the EC and RH data recorded by the sensors, and therefore represent a first order approximation to 

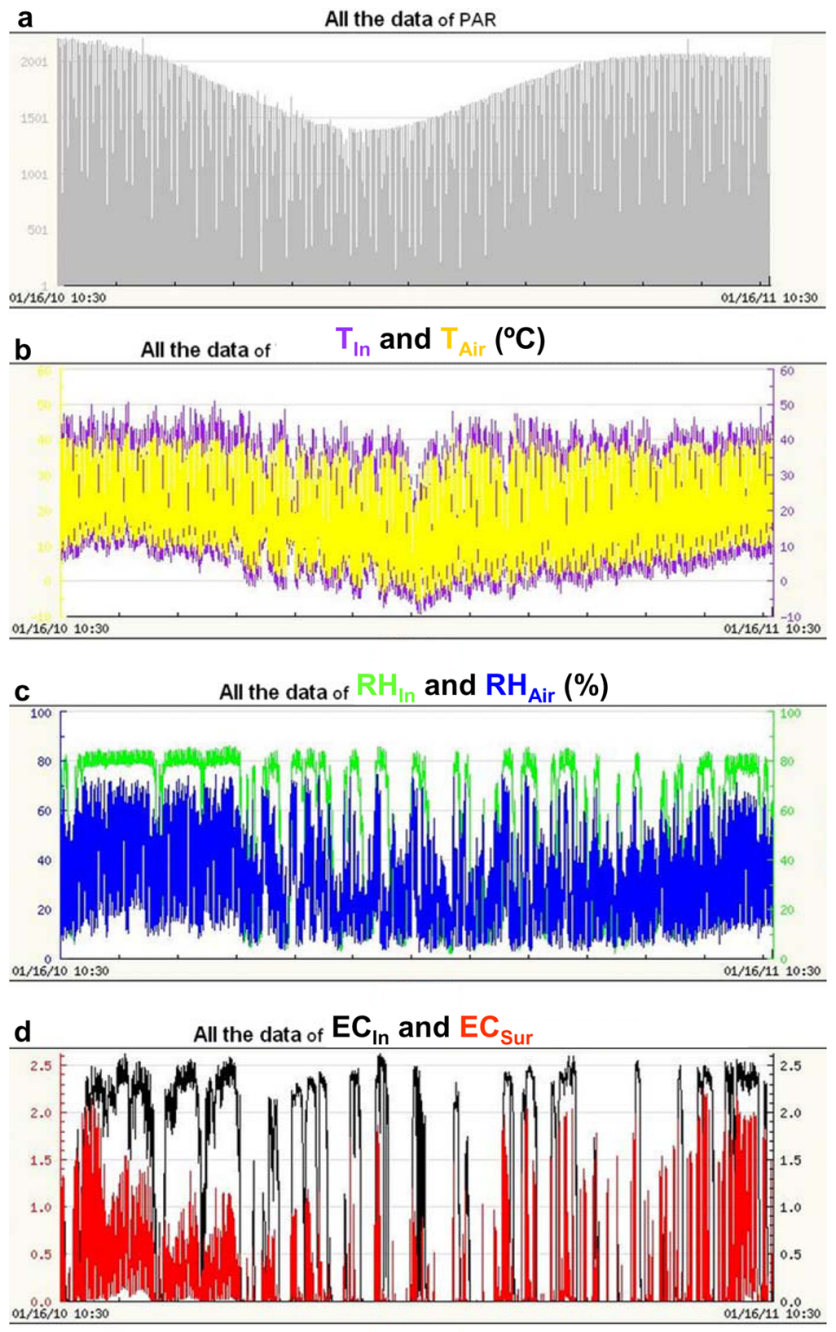

Fig. 2. Micro-environmental data collected over one year inside and outside halite pinnacles in the Yungay region. (a) Photosynthetic active radiation (PAR). (b) Temperature inside the pinnacle ( $T_{\mathrm{In}}$, purple line) and atmospheric temperature ( $T_{\text {Air }}$, yellow line). Note the higher temperature amplitudes inside the pinnacle. (c) Relative humidity inside the pinnacle $\left(\mathrm{RH}_{\text {In }}\right.$, green line) and air relative humidity $\left(\mathrm{RH}_{\text {Air }}\right.$, blue line). Note the long periods when $\mathrm{RH}_{\mathrm{In}}$ was above $75 \%$ (deliquescence relative humidity), while $\mathrm{RH}_{\text {Air }}$ never exceeded $75 \%$. (d) Electrical conductivity inside the halite pinnacle $\left(\mathrm{EC}_{\mathrm{In}}\right.$, black line) and surface electrical conductivity $\left(\mathrm{EC}_{\mathrm{Sur}}\right.$, red line). Note the long periods when $\mathrm{EC}_{\mathrm{In}}$ and also $\mathrm{EC}_{\text {Sur }}$ values were above 0 , indicating the presence of liquid water.

the conditions inside the pinnacles. However, our estimates clearly indicate that, while conditions outside the pinnacles were always extremely dry, the pinnacle interior remains wet for $5362 \mathrm{~h} \mathrm{yr}^{-1}$ containing pore water brine available to endolithic microorganisms during $61 \%$ of the year.

Our data show that halite pinnacles induce the condensation of liquid water at a RH much lower than $75 \%$, the deliquescence point of halite, and also retain liquid water for up to five weeks, suggesting that liquid water inside halite
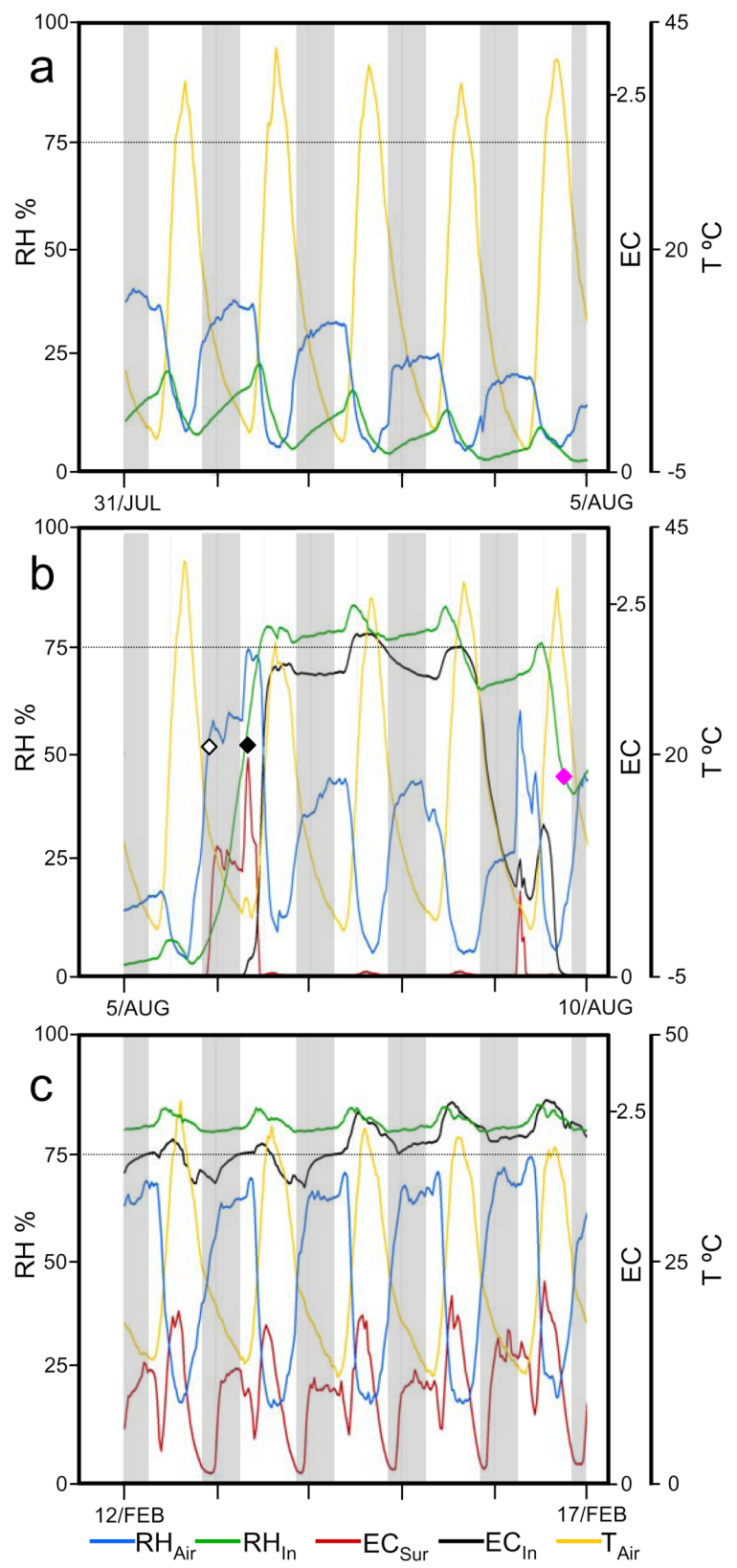

Fig. 3. Moisture conditions inside and outside the halite pinnacles. Grey vertical stripes indicate nighttime dark hours. (a) Dry stage when $\mathrm{RH}_{\text {Air }}$ and $\mathrm{RH}_{\text {In }}$ fall below $40 \%$ and $25 \%$ respectively, and EC sensors record null values. (b) Short wet event. Water condensation occurs first on the halite surface (white diamond), and is followed several hours later by capillary condensation in the colonization zone (black diamond); the pinnacle falls back to the dry stage after four days of wet internal conditions (pink diamond). (c) Portion of a 40-day-long wet stage, when $\mathrm{RH}_{\text {In }}$ is continuously above $75 \%$. Concurrently, $\mathrm{RH}_{\text {Air }}$ oscillates between 17-19\% (afternoons) and 70-74\% (nights and dawn). Positive EC values indicate liquid water inside the pinnacles and on their surface. Note that the max-

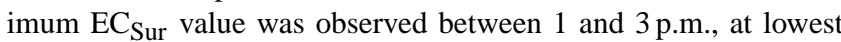
$\mathrm{RH}_{\text {Air }}$ and highest daily $T_{\text {Air }} \cdot \mathrm{RH}_{\text {Air }}=$ atmospheric $\mathrm{RH} ; T_{\text {Air }}=$ atmospheric $T ; \mathrm{RH}_{\mathrm{In}}=\mathrm{RH}$ in halite interior; $\mathrm{EC}_{\text {Sur }}=$ conductivity on halite surface; $\mathrm{EC}_{\mathrm{In}}=$ conductivity in halite interior. 


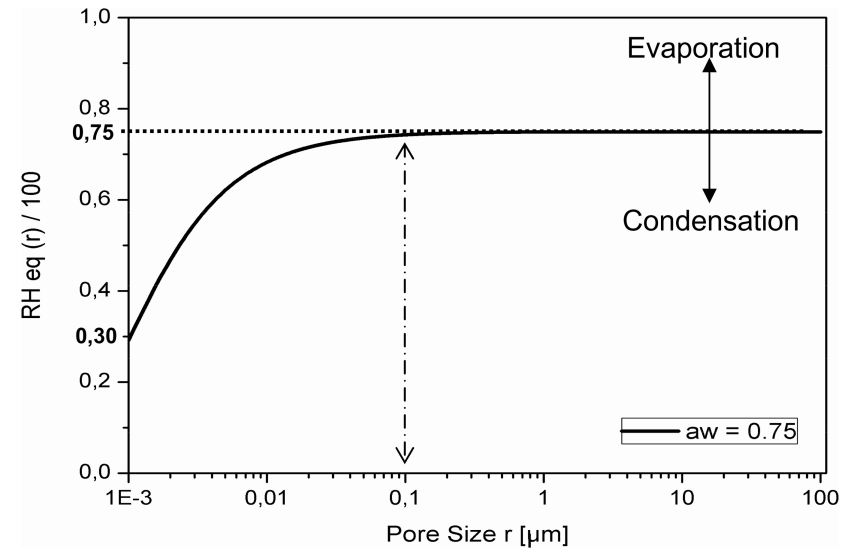

Fig. 4. Theoretical water evaporation/condensation equilibrium in halite. The model estimates the equilibrium relative humidity $\left(\mathrm{RH}_{\mathrm{eq}}\right)$ of a NaCl-saturated solution as a function or pore radius (Benavente et al., 2003). See Supplement for more details.

can occur in much drier conditions and for longer periods of time than previously thought (Davila et al., 2008). This fact points to additional mechanisms of water acquisition and retention in the pinnacles, which are described below. A similar laboratory observation has been described for aqueous sea-salt and $\mathrm{NaCl}$ aerosols, which start to absorb water at $\mathrm{RH}$ much lower than the DRH and exist as internally mixed phase particles (liquid/solid) over a wide range of $\mathrm{RH}$ values (Tang et al., 1997; Koop et al., 2000). Below, we propose a mechanism to explain water condensation at RH below DRH, and water retention for prolonged periods of time, inside the halite pinnacles.

\subsection{Capillary condensation in small pore spaces}

The DRH of a mineral phase inside a rock and the evaporation rates of interstitial liquid solutions not only depend on the temperature and salt concentration of the solution, but also on the small pore space distribution of the rock (Benavente et al., 2003). We modeled the equilibrium RH $\left(\mathrm{RH}_{\mathrm{eq}}\right)$ of a saturated $\mathrm{NaCl}$ solution as a function of porespace using a derivation of the Kelvin model (Benavente et al., 2003). This model predicts that liquid water will nucleate from the vapor phase inside a given pore when $\mathrm{RH}>\mathrm{RH}_{\mathrm{eq}}$. Assuming that the liquid solution is saturated with the host salt, the model predicts a $\mathrm{RH}_{\mathrm{eq}}$ inside halite between $29 \%$ and $75 \%$ for a pore-radius between 1 and 100 nanometers, respectively (Fig. 4). The range of RH that allows for liquid water condensation in nanometer-size pores overlaps the $\mathrm{RH}$ range at which we observed liquid water condensation inside the pinnacles, suggesting that the presence of nano-porous halite in the pinnacles could be responsible for water vapor condensation at RH significantly lower than DRH. Once liquid water nucleates in the smallest pores, the model predicts a positive feedback mechanism for liquid wa- ter condensation, as long as $\mathrm{RH}>\mathrm{RH}_{\mathrm{eq}}$, until equilibrium is reached at $\mathrm{RH}=75 \%$, which is the $\mathrm{RH}_{\mathrm{eq}}$ of a saturated solution of $\mathrm{NaCl}$. This is in fact observed inside the pinnacles at the onset of wet stage, when RH and conductivity inside the pinnacles increase abruptly to $75 \%$ and saturation levels, respectively.

Additionally, evaporation rates of brines are much lower than those of pure water, because the dissolved salt lowers the vapor pressure of the solution (Desbois et al., 2008). Hence, brines will tend to stay in the liquid phase longer than pure water. Moreover, our derivation of the Kelvin model indicates that, in the presence of nano-pores, $\mathrm{RH}$ inside the halite must fall below $30-40 \%$ in order to evaporate the pore-water brine in the smallest pores. Hence, the existence of nanopores inside the halite pinnacles could also theoretically explain their high efficiency at retaining this liquid water from evaporation until $\mathrm{RH}$ falls to very low values $(\sim 41.8 \%)$. The presence of such nano-pores is indeed supported by mercury porosimetry data (Table 1), which revealed that, between 5 and $11 \%$ of the total porosity of the halite, pinnacles correspond to pores below $100 \mathrm{~nm}$. Additionally, the outer, noncolonized layer of the halite, with an average pore radius of $42.6 \mathrm{~nm}$ and as little as $9.4 \%$ total porosity, could act as a diffusion-limiting layer preventing water vapor exchange with the atmosphere. In the next section, we demonstrate the presence of such a nano-porous halite phase by direct observation using a diversity of electron microscope techniques.

\subsection{Internal structure, nano-pores, and pore brine in halite pinnacles}

Above, we proposed that the tendency shown by the pinnacles to condense liquid water at a very low $\mathrm{RH}$, and to retain this pore brine for prolonged periods of time, could be linked to the internal fabric (i.e. porosity and pore size distribution) of the pinnacles, which is characteristic to the hyperarid core environment of the Atacama Desert. To test this theory, we captured detailed low-temperature, high-resolution environmental scanning electron microscopy images of the pinnacle interior (Figs. 5-8). Imaging was complemented by energy dispersive X-ray spectroscopy (EDS) microanalysis. Our challenge was to identify and characterize a nano-porous halite phase with pores smaller than $100 \mathrm{~nm}$, as indicated by mercury intrusion porosimetry.

\subsubsection{Low temperature SEM}

A low-temperature (or cryo-) preparation technique for scanning electron microscopy (LT-SEM) is essential to observe a sample in its "natural" state (Ascaso et al., 2002; Souza-Egipsy et al., 2002). Visualization of cryo-fixed cryofractured samples shows the internal structure of the halite's features. First, we observed a natural halite sample equilibrated at $\mathrm{RH}=75 \%$, in which the abundant presence of brine was expected due to deliquescence (Davila et al., 2008). 


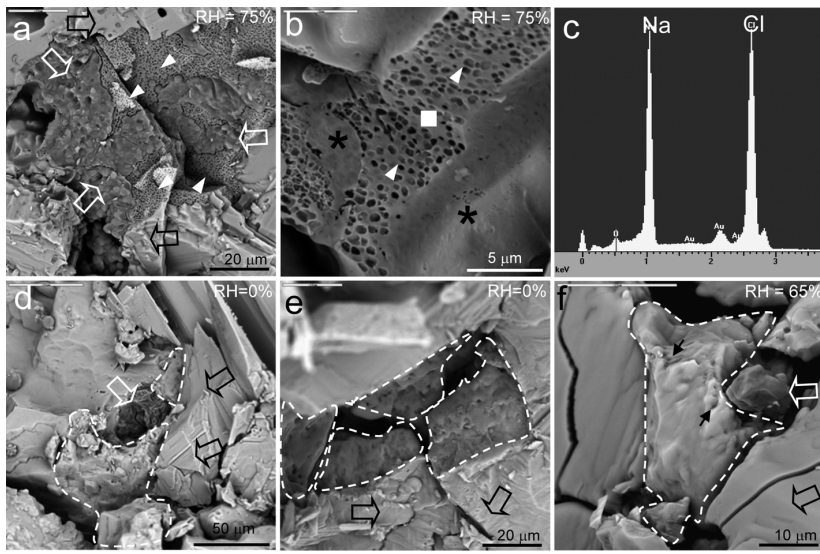

Fig. 5. LT-SEM images of the endolithic habitat inside the pinnacles equilibrated at different RH values. (a) Image of cyanobacterial cells forming aggregates (white open arrows) embedded in the hydrohalite after sublimation of brine (white arrowheads) in a sample equilibrated at $75 \%(\mathrm{DRH})$; black open arrows point to fractured halite crystals. (b) Detailed image of the partially fractured and etched hydrohalite revealing the foam-like structure (white arrowheads); note that not fractured feature shows smooth surface (asterisks). (c) EDS microanalysis of the brine remnant (square in (b) shows analytical point) reveals $\mathrm{Na}$ and $\mathrm{Cl}$ as main elements. (d) Fractured halite crystals (black open arrows) and a phase with pitted surface (outlined by dotted line) filling the space among large halite crystals equilibrated at $\mathrm{RH}=0 \%$; white open arrows point to microbial cell aggregate. (e) Grain boundaries between halite crystals (black open arrows) filled with the phase with pitted surface (outlined by dotted line) equilibrated at $\mathrm{RH}=0 \%$. (f) Fractured halite crystals (black open arrow) and phase with pitted surface (outlined by dotted line) filling the space between large halite crystals equilibrated at $\mathrm{RH}=65 \%$; white open arrows point to microbial cell aggregate and black arrows point to micropores.

Because of the rapid cooling by plunge freezing of the halite equilibrated at the deliquescence point in liquid nitrogen, the grain boundary brine is transformed into ice $\left(\mathrm{H}_{2} \mathrm{O}\right)$ and hydrohalite $\left(\mathrm{NaCl} 2 \mathrm{H}_{2} \mathrm{O}\right)$ (Bodnar, 1993). By freeze-drying the sample at this point, the sublimation of ice in the sample is induced and the hydrohalite can be observed in place of the grain boundary brine. Indeed, this analytical approach revealed the presence of brine remnants in the form of a sponge- or foam-like precipitate (as shown in Fig. 5a and b). The same pattern was observed by Schenk et al. (2006), Blackford (2007), Blackford et al. (2007) and Desbois et al. $(2008,2011,2012)$ in laboratory-processed halite samples. According to these authors, the "foam" structure is produced by the sublimation of ice crystals leaving behind voids in the hydrohalite precipitate. These results confirm the prediction by Davila et al. (2008) that, at the deliquescence point of halite, considerable brine forms inside the pinnacles, practically filling spaces between the larger crystals. This brine is therefore accessible to endolithic microorganisms.
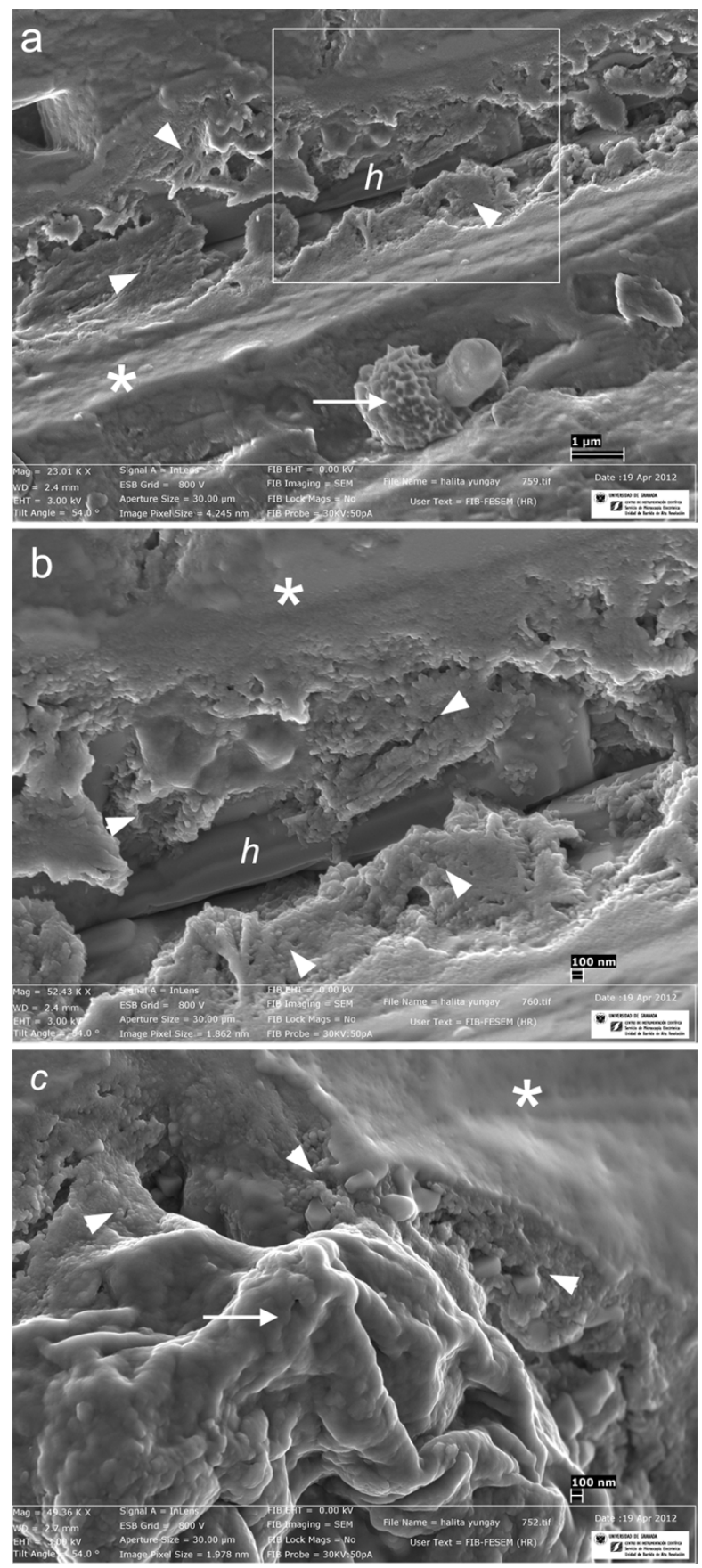

Fig. 6. HR-SEM images of desiccated halite. (a) General view of halite crystal $(h)$ covered by a nano-porous phase (white arrowheads) containing pores $<100 \mathrm{~nm}$; arrows point to microorganism cell. (b) Detailed HR-SEM image from square area in (a) of nanoporous phase (white arrowheads). (c) Microbial aggregate (arrow) in close contact with nano-porous phase (white arrowheads). Note that asterisks in all images show smooth skin surface coating the nano-porous phase. 


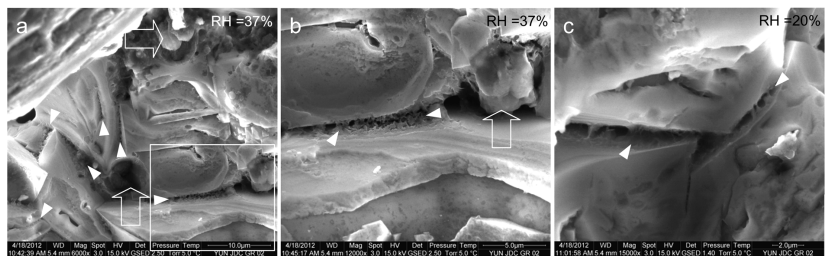

Fig. 7. ESEM images of halite large crystals and grain boundaries equilibrated at low RH. (a) General view shows grain boundaries among halite crystals (white arrowheads) and microbial cell aggregates (open white arrows) equilibrated at RH $37 \%$. (b) Detailed ESEM image from the square area in (a) the nano-porous phase (white arrowheads) filling the grain boundary; the white open arrow points to the microbial cell aggregate. (c) The ESEM image shows the nano-porous phase (white arrowheads) filling the grain boundary; halite equilibrated at RH $20 \%$.

Since the cryo-fixation and freeze-drying of samples gives rise to secondary morphologies (i.e. foam-like precipitates) due to brine sublimating along grain boundaries, we chose to perform all our observations on samples equilibrated at $\mathrm{RH}<75 \%$ without freeze-drying. An example of this approach is shown in the LT-SEM images in Fig. 5d-f. Thus, the images in Fig. 5d and e correspond to a dehydrated (equilibrium $\mathrm{RH}=0 \%$ ) halite sample and Fig. $5 \mathrm{f}$ is an image of a halite sample equilibrated at $65 \% \mathrm{RH}$. At the micro-scale, the grain boundaries between larger halite crystals are not filled with a foam-like matrix, but instead by a phase with a pitted surface (outlined structures in Fig. 5d-f), clearly distinguishable from the larger, smooth halite crystals. At higher magnification, this phase shows the presence of small randomly distributed pores (black arrows in Fig. 5f), and endolithic cyanobacteria are frequently observed in close association with this phase.

\subsubsection{High-resolution SEM}

To further characterize the different halite morphologies inside the pinnacles, we used high-resolution SEM (HR-SEM) with an innovative in-lens SE detection system. These images are provided in Fig. 6a-c. The lower-magnification image in Fig. 6a shows microbial cells, large halite crystals $(h)$, and a nano-porous phase between grain boundaries (indicated by white arrowheads). At higher magnification (Fig. 6b), the nano-porous phase is seen to be composed of pores smaller than $100 \mathrm{~nm}$. This phase reveals a smooth exterior surface akin to a skin layer or film (asterisks in Fig. 6a-c).

\subsubsection{Environmental SEM}

For HR-SEM observation, carbon-coated dehydrated samples are examined in high vacuum conditions, which could eliminate all traces of water. For this reason, we tried to identify the nano-porous phase by environmental scanning elec-

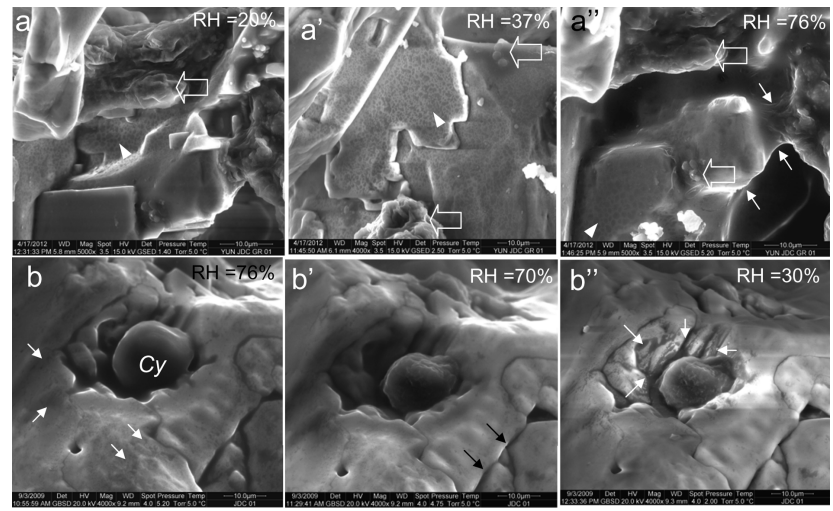

Fig. 8. ESEM sequences of in situ halite hydration (a-a") and dehydration (b-b") processes. (a) ESEM image of halite crystals and microbial cell aggregates (open white arrow) equilibrated at $\mathrm{RH}=20 \%$; note the observed foam-like patterns coating the surface of large halite crystals (arrowhead). (a') Detailed view of the foam phase coating the surface of halite crystals at $\mathrm{RH}=37 \%$; white open arrows point to microbial cell aggregates. (a") ESEM image from the same area as in (a) after deliquescence $(\mathrm{RH}=76 \%)$; white open arrows point to the microbial cell aggregates, and white arrows point to the liquid brain meniscus. Note that at such high $\mathrm{RH}$ the foam-like phase was still partially observed (white arrowhead). (b-b") ESEM images showing dehydration of halite with cyanobacteria cell small aggregate $(\mathrm{Cy})$ from $\mathrm{RH}=76 \%$ (image b) to $\mathrm{RH}=30 \%$ (image $\mathbf{b}^{\text {") }}$; white arrows point to brine solution; black arrows (image b') point to partially evaporated brine in narrow fissure. Note how the cyanobacterial aggregate shrinks with decreasing $\mathrm{RH}$ and brine evaporation.

tron microscopy (ESEM). This technique allows the in situ visualization of samples in their natural hydration state in the absence of a preparation procedure (i.e. without drying or carbon coating) across a controlled and equilibrated range of RH and temperature values.

First, natural samples of halite collected at a RH of $37 \%$ and kept at this RH throughout storage were used for this experiment. The results of this study are shown in the ESEM images in Fig. 7a-c. The low magnification image in Fig. 7a shows the microbial cell aggregates (open arrows) and large halite crystals separated by grain boundary spaces (white arrows in Fig. 7a). Surprisingly, higher magnification images (Fig. 7b and c) show that almost all the halite grain boundary spaces are occupied by the microcrystalline- and/or nanoporous phase (white arrowheads in Fig. 7b and c), revealing micropores as small as $1 \mu \mathrm{m}$ in diameter. The micromorphological appearance of this phase was very similar to that observed by HR-SEM. This phase was also observed within the sample equilibrated to a RH of $20 \%$ (Fig. 7c), thus indicating that this phase was stable in natural conditions of low relative humidity.

Next, we examined halite samples in graded stages of in situ hydration (Fig. 8a-a") and dehydration (Fig. 8b-b"). These procedures were performed inside the ESEM chamber. 


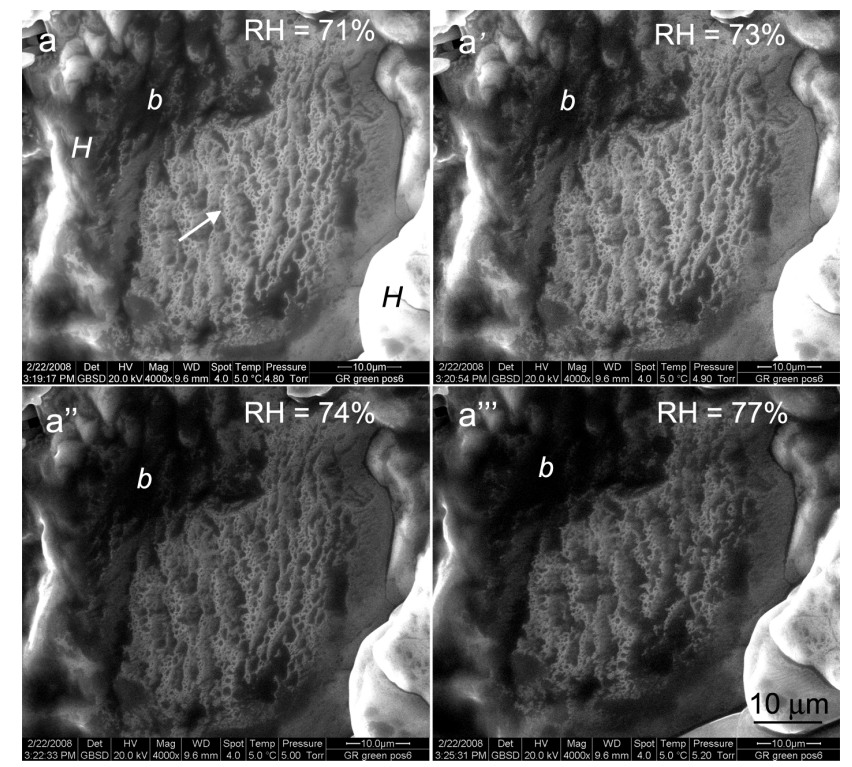

Fig. 9. Sequence of ESEM images (a-a"') of a halite sample showing the foam-like phase (arrow in a) among larger halite crystals $(H)$ in sample hydrated inside the ESEM chamber from RH of $71 \%$ to $77 \%$; (b), brine solution.

Halite samples equilibrated at $20 \%$ were observed before and after increasing the RH to $37 \%$ (Fig. 8a and a', respectively). This kind of visualization distinctly reveals the presence of a foam-like structure covering large halite crystal at these low RH conditions (Fig. 8a and a'). Careful visualization shows that the foam phase has a smooth skin surface as noted in the ESEM images (Fig. 8a and a'). When the $\mathrm{RH}$ was raised above the deliquescence point, the foam-like phase began to fade and the presence of liquid brine was observed (Fig. 8a"). However, even above the DRH, the foam phase could still be observed in some areas of the sample (white arrowhead in Fig. 8a"). Another series of ESEM images (Figs. 8b-b") shows the dynamics of pore brine in the presence of a cyanobacterial cell aggregate during a dehydration cycle (i.e. decreasing RH from 76 to $30 \%$ ). At high RH, the pore brine may be observed around the cyanobacterial aggregate and filling small cracks in the halite (Fig. 8b). The aggregate is turgid due to the presence of water. Pore brine progressively disappears around the cyanobacterial cells and in the narrow cracks as RH deceases to $70 \%$ (Fig. 8b'). After a time-period of $98 \mathrm{~min}$ when $\mathrm{RH}$ is $30 \%$, the cyanobacterial cell aggregate shows evidence of shrinkage due to water loss, although small pockets of brine (dark spots) can still be observed around the aggregate (white arrows in Fig. 8b"). The composition of this brine $\left(\mathrm{NaCl}\right.$ and $\left.\mathrm{H}_{2} \mathrm{O}\right)$ was confirmed by EDS microanalysis. This experiment demonstrates that even at a $\mathrm{RH}$ of $30 \%$ a small quantity of brine can still persist in the halite.
Finally, we followed the morphological changes produced in the foam-like phase at a $\mathrm{RH}$ around the deliquescence point. To this end, the halite sample was equilibrated stepwise at a RH of 71 to $77 \%$. Changes in the morphology of the foam phase were recorded at 71, 73, 74 and $77 \% \mathrm{RH}$ (as shown in Fig. 9a-a"'). In all the ESEM images, the foam phase between larger crystals can be observed. The intensity of the SE signal is highly affected by the BSE signal, which depends on the mean atomic number of the target. Hence, ESEM served to distinguish between the $\mathrm{NaCl}$ precipitates (brighter signal) and brine solution (darker signal). Accordingly, the dark areas in Fig. 9 indicate the presence of brine. As can be observed in the sequence of images, the dark areas become more extensive as the RH approaches the deliquescence point. When RH reaches $77 \%$, partial dissolution of the granular phase occurs (Fig. 9a"'), as evidenced by the extensive dark area and larger dark spots in the foam-like phase. It is important to note that ESEM observations confirm that the foam phase is present and stable at $\mathrm{RH}=71 \%$, i.e. below the deliquescence point.

In summary, the following conclusions can be drawn from the different electron microscopy observations made:

1. At the DRH $(\mathrm{RH}=75 \%)$, abundant brine forms inside the halite pinnacles filling the pore spaces between large halite crystals and this brine could be accessible to endolithic microorganisms. This was established by the presence of a foam-like hydrohalite structure observed by LT-SEM.

2. Grain boundaries and large halite crystals appear covered by a nano-porous phase consisting of small pores $<100 \mathrm{~nm}$ in diameter (observed by HR-SEM at $\mathrm{RH}=0 \%$ ) or a foam-like phase (observed by ESEM from a $\mathrm{RH}$ of 20 to $77 \%$ ). These phases feature a smooth film coating the large halite crystals.

3. The above-mentioned phases partially dissolve into liquid brine during halite deliquescence, and it thus seems it is the halite phase that most rapidly responds to changes in RH within the halite pinnacles. We propose that the small pore spaces within these phases correspond to the smallest porosity measured by mercury intrusion porosimetry, and are responsible for the occurrence of liquid water at $\mathrm{RH}<\mathrm{DRH}$ indicated by our microclimate data.

\section{Conclusions}

Endolithic communities inside halite pinnacles in the Atacama Desert take advantage of the moist conditions that are created by the halite substrate in the absence of rain, fog or dew. The tendency of the halite to condense and retain liquid water is enhanced by the presence of a nano-porous phase with a smooth surface skin, which covers large crystals and 
fills the larger pore spaces inside the pinnacles. This phase has pores smaller than $100 \mathrm{~nm}$ (MIP and SEM data), which would theoretically allow for capillary water condensation at $\mathrm{RH}<\mathrm{DRH}$ (i.e. $50-55 \%$ instead of $75 \%$ ), and for water retention for prolonged periods of time. Endolithic microbial communities were observed as intimately associated with this hypothetical nano-porous phase. While halite endoliths must still be adapted to stress conditions inside the pinnacles (i.e. low water activity due to high salinity), these observations show that hygroscopic salts such as halite become oasis for life in extremely dry environments, when all other survival strategies fail.

Our findings have implications for the habitability of extremely dry environments, as they suggest that salts with properties similar to halite could be the preferred habitat for life close to the dry limit on Earth and elsewhere (Davila et al., 2010). It is particularly tempting to speculate that the chloride-bearing evaporites recently identified on Mars (Osterloo et al., 2008) may have been the last, and therefore most recently inhabited, substrate as this planet transitioned from relatively wet to extremely dry conditions.

\section{Supplementary material related to this article is available online at: http://www.biogeosciences.net/9/ 2275/2012/bg-9-2275-2012-supplement.pdf.}

Acknowledgements. The authors thank S. Valea and B. Camara for help with installing the microweather station and K. Wierzchos for data treatment. We are grateful to J. A. Nienow for initial idea of electrical conductivity measurements and B. Gómez Silva for logistic support in Yungay. We also acknowledge L. F. Pinto, T. Carnota and A. González for technical assistance and A. Burton for reviewing the English. J. W., C. A. and A. F. D. were supported by grant CGL2010-16004 and C. A. by grant CTM2009-12838C04-03 from the Spanish Ministry of Science and Innovation, and A. F. D. and J. W. were supported by grant NNX12AD61G of the NASA Exobiology program. Helpful suggestions from two anonymous reviewers were highly appreciated.

Edited by: E. J. Javaux

\section{References}

Ascaso, C., Wierzchos, J., Souza-Egipsy, V., de los Ríos, A., and Rodrigues, J. D.: In situ evaluation of the biodeteriorating action of microorganisms and the effects of biocides on carbonate rock of the Jeronimos Monastery (Lisbon), Int. Biodeter. Biodegrad., 49, 1-12, 2002.

Azúa-Bustos, A., González-Silva, C., Mancilla, R. A., Salas, L., Gómez-Silva, B., McKay, C. P., and Vicuña, R.: Hypolithic Cyanobacteria supported mainly by fog in the coastal range of the Atacama Desert, Microb. Ecol., 61, 568-581, 2011.

Benavente, D., García del Cura, M. A., and Ordóñez, S.: Salt influence on evaporation from porous building rocks, Constr. Build. Mater., 17, 113-122, 2003.
Blackford, J. R.: Sintering and microstructure of ice: a review, J. Phys. D: Appl. Phys., 40, R355-R385, 2007.

Blackford, J. R., Jeffree, C. E., Noake, D. F. J., and Marmo, B. A.: Microstructural evolution in sintered ice particles containing $\mathrm{NaCl}$ observed by low-temperature scanning electron microscope, P. I. Mech. Eng. L.-J. Mat., 221, 151-156, 2007.

Bodnar, R. J.: Revised equation and table for determining the freezing point depression of $\mathrm{H}_{2} \mathrm{O}-\mathrm{NaCl}$ solutions, Geochim. Cosmochim. Acta, 57, 683-684, 1993.

Büdel, B., Bendix, J., Bicker, F. R., and Green, A. T. G.: Dewfall as a water source frequently activates the endolithic cyanobacterial communities in the granites of Taylor Valley, Antarctica, J. Phycol., 44, 1415-1424, 2008.

Connon, S. A., Lester, E. D., Shafaat, H. S., Obenhuber, D. C., and Ponce, A.: Bacterial diversity in hyperarid Atacama desert soils, J. Geophys. Res.-Biogeo., 112, G04S17, doi:10.1029/2006JG000311, 2007.

Davila, A. F., Gómez-Silva, B., de los Ríos, A., Ascaso, C., Olivares, H., McKay, C. P., and Wierzchos, J.: Facilitation of endolithic microbial survival in the hyperarid core of the Atacama Desert by mineral deliquescence, J. Geophys. Res.-Biogeo., 113, G01028, doi:10.1029/2007jg000561, 2008.

Davila, A. F., Duport, L. G., Melchiorri, R., Janchen, J., Valea, S., de los Ríos, A., Fairen, A. G., Mohlmann, D., McKay, C. P., Ascaso, C., and Wierzchos, J.: Hygroscopic salts and the potential for life on Mars, Astrobiol., 10, 617-628, 2010.

de los Ríos, A., Valea, S., Ascaso, C., Davila, A., Kastovsky, J., McKay, C. P., Gómez-Silva, B., and Wierzchos, J.: Comparative analysis of the microbial communities inhabiting halite evaporites of the Atacama Desert, Int. Microbiol., 13, 79-89, 2010.

Desbois, G., Urai, J. L., Burkhardt, C., Drury, M. R., Hayles, M., and Humbel, B.: Cryogenic vitrification and 3D serial sectioning using high resolution cryo-FIB SEM technology for brinefilled grain boundaries in halite: First results, Geofluids, 8, 6072, 2008.

Desbois, G., Urai, J. L., Kukla, P. A., Konstanty, J., and Baerle, C.: High-resolution 3D fabric and porosity model in a tight gas sandstone reservoir: a new approach to investigate microstructures from mm- to nm-scale combining argon beam cross-sectioning and SEM imaging, J. Petrol. Sci. Engineering., 78, 243-257, 2011.

Desbois, G., Urai, J. L., Kukla, P. A., Wollenberg, U., PérezWillard, F., Radí, Z., and Riholm, S.: Distribution of brine in grain boundaries during static recrystallization in wet, synthetic halite: Insight from broad ion beam sectioning and SEM observation at cryogenic temperature, Contrib. Mineral. Petrol., 163, 19-31, 2012.

Ebert, M.: Environmental scanning electron microscopy as a new technique to determine the hygroscopic behaviour of individual aerosol particles, Atmos. Environ., 36, 5909-5916, 2002.

Ewing, S. A., Yang, W., DePaolo, D. J., Michalski, G., Kendall, C., Stewart, B. W., Thiemens, M., and Amundson, R.: Nonbiological fractionation of stable Ca isotopes in soils of the Atacama Desert, Chile, Geochim. Cosmochim. Acta, 72, 1096$1110,2008$.

Friedmann, E. I.: Adaptations of cryptoendolithic lichens in the Antarctic Dry Valleys, Origins of Life, 12, 320, doi:10.1007/BF00926903, 1982. 
Golubic, S., Friedmann, I., and Schneider, J.: The lithobiontic ecological niche, with special reference to microorganisms, J. Sediment. Petrol., 51, 475-478, 1981.

Hajnos, M., Lipiec, J., Swieboda, R., Sokolowska, Z., and Witkowska-Walczak, B.: Complete characterization of pore size distribution of tilled and orchard soil using water retention curve, mercury porosimetry, nitrogen adsorption, and water desorption methods, Geoderma, 135, 307-314, 2006.

Henschel, J. R. and Seely, M. K.: Ecophysiology of atmospheric moisture in the Namib Desert, Atmos. Res., 87, 362-368, 2008.

Kidron, G.: Microclimate control upon sand microbiotic crusts, western Negev Desert, Israel, Geomorphology, 36, 1-18, 2000.

Koop, T., Kapilashrami, A., Molina, L. T., and Molina, M. J.: Phase transitions of sea-salt/water mixtures at low temperatures: implications for ozone chemistry in the polar marine boundary layer, J. Geophys. Res.-Atmos., 105, 26393-26402, 2000.

Kuhlman, K. R., Venkat, P., La Duc, M. T., Kuhlman, G. M., and McKay, C. P.: Evidence of a microbial community associated with rock varnish at Yungay, Atacama Desert, Chile, J. Geophys. Res., 113, G04022, doi:10.1029/2007jg000677, 2008.

Lange, O. L., Meyer, A., and Büdel, B.: Net photosynthesis activation of a desiccated cyano-bacterium without liquid water in high air humidity alone. Experiments with Microcoleus Sociatus isolated from a desert soil crust, Functional Ecology, 8, 52-57, 1994.

Lester, E. D., Satomi, M., and Ponce, A.: Microflora of extreme arid Atacama Desert soils, Soil Biol. Biochem., 39, 704-708, 2007.

McKay, C. P., Friedmann, E. I., Gómez-Silva, B., Cáceresvillanueva, L., and Andersen, D. T.: Temperature and moisture conditions for life in the of observations including the El Niño of 1997-1998, Astrobiol., 3, 393-406, 2003.

Navarro-González, R., Rainey, F. A., Molina, P., Bagaley, D. R., Hollen, B. J., De La Rosa, J., Small, A. M., Quinn, R. C., Grunthaner, F. J., Cáceres, L., Gómez-Silva, B., and McKay, C. P.: Mars-like soils in the Atacama Desert, Chile, and the dry limit of microbial life, Science, 302, 1018-1021, 2003.

Nienow, J. A.: Extremophiles: Dry Environments (including Cryptoendoliths), in: Encyclopedia of Microbiology, Elsevier, Oxford, 159-173, 2009.

Osterloo, M. M., Hamilton, V. E., Bandfield, J. L., Glotch, T. D., Baldridge, A. M., Christensen, P. R., Tornabene, L. L., and Anderson, F. S.: Chloride-bearing materials in the southern highlands of Mars, Science, 319, 1651-1654, 2008.
Palmer, R. J. and Friedmann, E. I.: Water relations, thallus structure and photosynthesis in Negev Desert lichens, New Phytologist, 116, 597-603, 1990a.

Palmer, R. J. and Friedmann, E. I.: Water relations and photosynthesis in the cryptoendolithic microbial habitat of hot and cold deserts, Microb. Ecol., 19, 111-118, 1990b.

Pueyo, J. J., Chong, G., and Jensen, A.: Neogene evaporites in desert volcanic environments: Atacama Desert, northern Chile, Sedimentology, 48, 1411-1431, 2001.

Schenk, O., Urai, J. L., and Piazolo, S.: Structure of grain boundaries in wet, synthetic polycrystalline, statically recrystallizing halite - Evidence from cryo-SEM observations, Geofluids, 6, 93104, 2006.

Souza-Egipsy, V., Ascaso, C., and Sancho, L. G.: Water distribution within terricolous lichens revealed by scanning electron microscopy and its relevance in soil crust ecology, Mycol. Res., 106, 1367-1374, 2002.

Tang, I. N. and Munkelwitz, H. R.: Composition and temperature dependence of the deliquescence properties of hygroscopic aerosols, Atmos. Environ.-A Gen., 27 A, 467-473, 1993.

Tang, I. N., Tridico, A. C., and Fung, K. H.: Thermodynamic and optical properties of sea salt aerosols, J. Geophys. Res.-Atmos., 102, 23269-23275, 1997.

Thiel, B. L., Bache, I. C., Fletcher, A. L., Meredith, P., and Donald, A. M.: An improved model for gaseous amplification in the environmental SEM, J. Microsc., 187, 143-157, 1997.

Warren-Rhodes, K. A., Rhodes, K. L., Pointing, S. B., Ewing, S. A., Lacap, D. C., Gómez-Silva, B., Amundson, R., Friedmann, E. I., and McKay, C. P.: Hypolithic cyanobacteria, dry limit of photosynthesis, and microbial ecology in the hyperarid Atacama Desert., Microb. Ecol., 52, 389-398, 2006.

Wierzchos, J., Ascaso, C., and McKay, C. P.: Endolithic cyanobacteria in halite rocks from the hyperarid core of the Atacama Desert, Astrobiol., 6, 415-422, 2006.

Wierzchos, J., Cámara, B., de los Ríos, A., Dávila, A. F., Sánchez Almazo, I. M., Artieda, O., Wierzchos, K., Gómez-Silva, B., McKay, C., and Ascaso, C.: Microbial colonization of Ca-sulfate crusts in the hyperarid core of the Atacama Desert: implications for the search for life on Mars, Geobiology, 9, 44-60, 2011. 